\title{
Kinematic, strength, and stiffness adaptations after a short-term sled towing training in athletes
}

\author{
P. E. Alcaraz ${ }^{1}$, J. L. L. Elvira ${ }^{2}$, J. M. Palao ${ }^{3}$ \\ ${ }^{1}$ Biomechanics Laboratory, Catholic University of San Antonio, Murcia, Spain, ${ }^{2}$ Sports Research Centre, Miguel Hernandez University \\ of Elche, Alicante, Spain, ${ }^{3}$ Department of Physical Education, Faculty of Sport Science, University of Murcia, San Javier, Spain \\ Corresponding author: Pedro E. Alcaraz, Facultad de Ciencias de la Actividad Física y del Deporte, Universidad Católica San \\ Antonio de Murcia, Campus de los Jerónimos s/n, 30107-Guadalupe, Murcia, Spain. Tel: +34 9682785 66, Fax: +34 968 278658 , \\ E-mail: palcaraz@ucam.edu
}

Accepted for publication 3 May 2012

\begin{abstract}
One of the most frequently used methods for training the sprint-specific strength is the sled towing. To date, no studies have been conducted to explore the effects of this method after a training period in well-trained athletes. The purpose of this study was to determine the effects of 4 weeks of resisted sprint training with sled towing. Twenty-two trained athletes experienced in the use of weighted sled (WS) participated in the study. They conducted the same 3-week training to level their initial condition. After that they were distributed in two groups, unresisted (UR) and WS training. They carried out the same 4-week, 2 days/week sprint-specific training, only
\end{abstract}

differing in that the experimental group performed sprints with a (WS) which caused a reduction of $7.5 \%$ of their maximum velocity. Pre- and posttest were conducted which included the measurement of sprint kinematics, muscular strength (including isoinertial, isokinetic, and jump measurements), and sprinting stiffness (leg and vertical). Results show different adaptations in the groups although no interaction effect was found. The WS group improved the velocity in the transition phase, while the UR group improved the velocity in the maximum velocity phase. No improvements in the height of the jump tests were found.
The ability to achieve a high maximum sprinting velocity is an important determinant of success in sports such as soccer, rugby, and American football and is widely considered a primary factor in athletic performance evaluation (Bangsbo et al., 1991; Hay, 1993). From a biomechanical point of view, linear sprinting is composed of acceleration, maximum velocity, and deceleration phases (Volkov \& Lapin, 1979), and therefore, each phase may require specific training methods (Alcaraz et al., 2008).

High-intensity strength training exercises with free weights and machines can improve the neural parameters of strength of musculature of the hips, quadriceps, and hamstrings (Rutherford \& Jones, 1986) and so increase an athlete's acceleration and maximum sprint velocity (Delecluse, 1997). However, many coaches believe that a sprint training program should also include strength-specific exercises, where the athlete uses the sport movement with an added resistance as the training exercise (Mero \& Komi, 1994; Delecluse et al., 1995; Delecluse, 1997), because the training principle of specificity states that for an exercise to be effective, it must maintain similar characteristics to the sport requirements (movement pattern, velocity, and action type specificity) (Behm \& Sale, 1993). For sprint training, such strength- specific exercises include towing a tire or weighted sled (WS), towing a parachute, wearing a weighted belt or vest, sprinting on a sand surface, and uphill sprinting (Young et al., 2001; Sheppard, 2004; Alcaraz et al., 2011). These modes of training are believed to develop specific mechanical power (force $\times$ velocity) and to increase stride length (Plisk, 2000). The use of these resisted sprinting techniques is common both in athletics and in a variety of team sports. However, there is very little experimental evidence that describes the merits of resisted sprinting or the different adaptations that may occur with the utilization of different resisted techniques (Cronin \& Hansen, 2006).

Various studies have focused on the acute effects of WS on the kinematics of sprinting in the acceleration (Letzelter et al., 1995; Lockie et al., 2003; Murray et al., 2005; Cronin et al., 2008) and the maximum velocity phase (Alcaraz et al., 2008). But there is little research examining the short-term effects of WS training program on the sprint kinematics (stride length, stride rate, ground contact time, joints and segment angles, etc.), strength (maximum isoinertial strength, isoinertial peak mechanical power, isokinetic peak torque, etc.), and leg and vertical stiffness, both in the acceleration and maximum velocity phases of sprinting (Zafeiridis et al., 
Alcaraz et al.

Table 1. General characteristics of participants

\begin{tabular}{llllll}
\hline & Age (years) & Mass $(\mathrm{kg})$ & Height $(\mathrm{cm})$ & Leg length $(\mathrm{cm})$ & Training experience $(\mathrm{years})$ \\
\hline WS, $n=11$ & $21.5 \pm 2.2$ & $69.8 \pm 14.7$ & $173.0 \pm 10.5$ & $90.0 \pm 7.1$ & $9.6 \pm 1.8$ \\
UR, $n=11$ & $20.9 \pm 3.1$ & $69.2 \pm 11.8$ & $179.2 \pm 8.4$ & $92.3 \pm 5.0$ & $8.2 \pm 2.3$ \\
\hline
\end{tabular}

WS, weighted sled; UR, unresisted.

2005; Harrison \& Bourke, 2009; Clark et al., 2010). In addition, the few studies reviewed have a great deal of limitations. For example, the participants in the Zafeiridis et al. (2005) and Clark et al. (2010) studies were physical education students or lacrosse players, respectively, with no experience in resisted sprint training. Furthermore, other studies have shown the effects of WS, but only on the acceleration phase, in non-athlete population (Kristensen et al., 2006; Spinks et al., 2007). These studies have shown an increase in the mechanical power, however, none of them have revealed an increase in the stride length.

As vertical stiffness is the product of peak vertical force divided by vertical center of mass (COM) displacement (McMahon \& Cheng, 1990), it would be expected that increases in force levels would mirror increases in vertical stiffness. At present, no research has been performed on how training can affect vertical and leg stiffness, only one study speculated that WS training would increase muscle stiffness and vertical force at each ground contact (Kafer \& Adamson, 1994). In this sense, special attention should be placed on the effects of these strategies of training both on vertical and leg stiffness. Brughelli and Cronin (2008) suggest that more training intervention studies are needed to investigate the effects of various training modes on both stiffness and running performance.

Despite the theoretical benefits associated with WS sprint training, research validating these training methods for improving the sprint performance key factors in experienced athletes is limited. Therefore, the aim of this study was to examine the effects of 4 weeks of resisted or unresisted (UR) sprint training programs on sprint kinematics, strength, and vertical and leg stiffness adaptations.

\section{Materials and methods}

\section{Subjects}

Thirty participants (male $n=20$, female $n=10$ ) national level athletes ( 24 sprinters, 2 long jumpers, and 4 decathletes) originally volunteered for the study. Finally, the study was completed by 22 athletes (14 men and 8 women). Participants who completed the study were distributed as follows: WS: six men and five women; UR: eight men and three women (Table 1). Dropout largely resulted from injuries sustained in sports competitions and subjects were omitted from the study when less than $85 \%$ of scheduled sessions were completed.

In addition, the following inclusion criteria were established: (a) age between 18 and 30 years; (b) personal best at $100 \mathrm{~m}$ between $10.5 \mathrm{~s}$ and $11.5 \mathrm{~s}$ for men, and $12.0 \mathrm{~s}$ and $13.0 \mathrm{~s}$ for women; (c) had to train four to six sessions per week, at least $2 \mathrm{~h}$ for those who trained only four sessions, and at least $1.5 \mathrm{~h}$ for those who trained six sessions; (d) had performed dynamic, freeweight strength training for at least 4 years on a regular basis with a minimum of 2 days a week, performing traditional lower-body training (i.e. half squats, etc.); and (e) had experience of WS training (minimum of two mesocycles in the last two seasons). Subjects read and signed statements of informed consent before participation in the study. The research was approved by the Catholic University of San Antonio Ethics Committee.

Design

A quasi-experimental, pretest/posttest randomized group design utilizing two training groups was employed to examine the shortterm effects of training with WS in well-trained athletes. Training and testing was conducted in the late October, November, and December when the athletes were performing resisted, acceleration, and maximum velocity training. After pretest, subjects were randomly assigned to one of two treatment conditions: (a) sprint training while towing WS; or (b) an active control group that completed the same training while UR. A load that causes a reduction of the maximum velocity of approximately $7.5 \%$ was used. This intensity was calculated with a regression equation designed for this purpose (Alcaraz et al., 2009).

Subjects completed 3 weeks of standardized resistance and sprint/jump training (Table 2) before a 4-week specific training phase. During the 3 -week standardization phase, subjects performed two sprint/jump sessions, two resistance training (RT) sessions per week (lower-body training was standardized whereas upper-body training was consistent with their previous training), and a regeneration session. The purpose of such training was to ensure subjects were performing similar training and that their training compliance was high before the specific training phase. Each sprint/jump session involved $1.5 \mathrm{~h}$ of supervised training in sprint running and vertical jumping technique (see Table 2). Lower-body RT sessions involved performing three sets of 10-12 repetitions at $75-80 \%$ of one-repetition maximum (1RM) of inclined leg press, hip extensions, and standing calf raise exercises, which were typical of the RT exercises used by the subjects in their previous training. Attendance at training sessions was monitored; all subjects performed at least six sprint/jump and six lower-body RT sessions over the 3-week period.

Testing sessions, performed over alternative days, included: (a) day 1: jump and $50 \mathrm{~m}$ sprint tests; (b) day 2: hip flexors and extensors isokinetic strength, maximum isoinertial strength (1RM) testing on the half squat, and peak mechanical power output in half squat exercise using resistances of $30 \%, 45 \%, 60 \%, 70 \%$, and $80 \%$ of 1RM; and (c) day 3: jump and $50 \mathrm{~m}$ sprint tests. Test order was repeated in the same order at the same time of day at post-training. Three days of rest separated the last training session of each phase from the start of testing.

After the 3-week standardization phase and the pretesting phase, subjects were divided into two training groups with male and female subjects distributed equally among the groups. Athletes were matched with respect to their sex, sprint performance 
Short-term sled towing training in athletes

Table 2. Sprint and jump sessions performed by all subjects. Training progressed from the standardization phase through the specific training phase. All sprints and jumps were performed maximally

\begin{tabular}{llll}
\hline Week 1 (standardization) & Week 1 (specific training) & Week 4 (specific training) & Rest \\
\hline Session 1 & & & \\
30 -min warm-up & 30 -min warm-up & 30 -min warm-up & Not applicable \\
$4 \times 30$-m sprint & $3 \times 20+30$-m flying sprint* & $6 \times 20+30$-m flying sprint* & $2-3$ min per repetition, 6 min per set \\
$3 \times 3$ two-leg CMJ & $3 \times 30$-m bounding & $6 \times 30$-m bounding & $1-3$ min per set \\
10-min cool down & 10 -min cool down & 10 -min cool down & Not applicable \\
Session 2 & 30 -min warm-up & 30 -min warm-up & Not applicable \\
30 -min warm-up & $3 \times 50$-m sprint & $4 \times 50$-m sprint & $2-3$ min per repetition, 6 min per set \\
$3 \times 30$-m resisted sprint & $3 \times 20+30$-m flying sprint ${ }^{*}$ & $6 \times 20+30$-m flying sprint* & $1-3$ min per set \\
$3 \times 3$ two-leg CMJ & 10 -min cool down & 10 -min cool down & Not applicable \\
10 -min cool down &
\end{tabular}

*The flying sprints sets were carried out with a sled towing by the weighed-sled group.

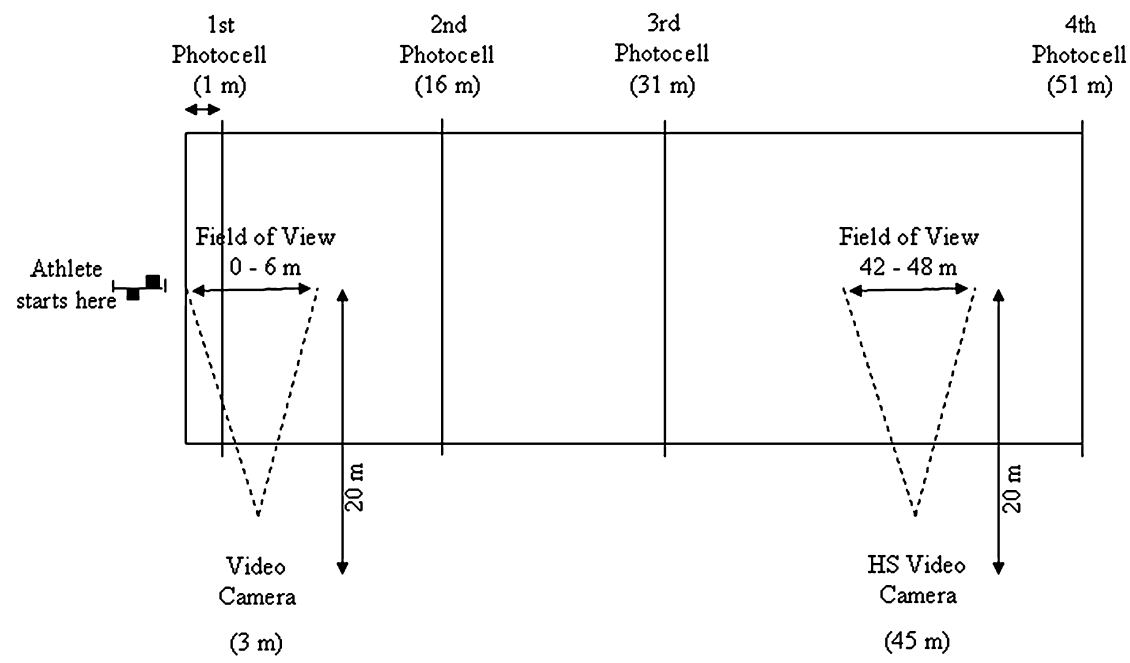

Fig. 1. The experimental setup used during data collection.

(100 m), and athletic discipline, and then randomly allocated to either the WS or the UR group. In the experimental phase, the same structure used in the standardization phase was maintained, the only difference was in the sprint running method used in the training groups.

\section{Testing}

\section{Sprint testing}

Subjects performed four 50-m runs (two each day) of maximal effort sprint from the starting blocks, four photoelectric cells (BioMedic, Barcelona, Spain) were placed along of the 50-m sprint to record the sprint times at $1,16,31$, and $51 \mathrm{~m}$ from the start line (Fig. 1). The first gate was placed $1 \mathrm{~m}$ from the start line to avoid being influenced by the reaction time. The gates were placed at the approximate height of the hip. Simultaneously to the sprint times, the maximum velocity for the sprints was measured through the use of radar (StalkerPro Inc., Plano, Tex) with a record data frequency of $33 \mathrm{~Hz}$. The warm-up and the sprint conditions were similar to those used in the sprint/jump sessions. The rest period typically lasted about $6 \mathrm{~min}$, which is sufficient for full recovery from repeated maximal sprints of short duration (Harris et al., 1976). The wind velocity for all trials was measured using a wind gauge (Cantabrian, Cambridge, UK). Trials in which the wind was not between $\pm 2 \mathrm{~m} / \mathrm{s}$ were repeated. The faster trial was used for the analysis.

\section{Vertical jump tests}

Different jump tests [squat jump (SJ), modified SJ, countermovement jump (CMJ), and drop jump (DJ) from a $0.5 \mathrm{~m}$ height] were performed on an extensometric force platform (Dinascan/Instituto de Biomecánica de Valencia, Valencia, Spain). In all jumps, the subjects were instructed to keep their hands on their waist at all times to minimize any contribution to jump impulse by the upper body. Each subject performed a practice trial for each of the movements before performing the test trials. The SJs were performed starting from a $90^{\circ}$ (traditional) or $120^{\circ}$ (modified) knee angle position, and no countermovement was permitted. If any $\mathrm{CMJ}$ was detected on force-time display, the subject was required to repeat that trial. In the DJ, subjects were instructed to minimize contact time on the force platform and maximize jump height. The force-time traces for the SJs and CMJs were analyzed to obtain four dependent variables - namely: jump height, absolute and relative mechanical power, and force at $100 \mathrm{~ms}\left(F_{100}\right)$. The start of concentric contraction was defined as the point where the force readings were $10 \mathrm{~N}$ greater than the average of the force readings 


\section{Alcaraz et al.}

when the subject was static in the SJ starting position. Jump heights $(\mathrm{JH})$ were calculated from the takeoff vertical velocity $\left(v^{i}\right)$ using the following equation: $\mathrm{JH}=v^{i 2} \cdot 2 g^{-1}$. Absolute and relative mechanical power was calculated as follows: vertical force $\times$ instantaneous vertical velocity of the system's center of mass. Force at $100 \mathrm{~ms}$ was simply obtained by finding the force at $100 \mathrm{~ms}$ from the start of the contraction [Force at $100 \mathrm{~ms}$ was used because the impulse-momentum relationship (Newton's second law) completely links kinetics to $(r=1.0)$ movement kinematics (Kaneko et al., 1983)].

Finally, leg and vertical stiffness $(K)$ were estimated based on the modeling of the force-time curve from mechanical parameters: body mass, forward velocity, leg length, flight time, and contact time (Morin et al., 2005). Flight time, contact time and forward velocity were obtained from the photogrammetric analysis.

\section{Kinematic analysis}

A two-dimensional (2D) kinematic analysis was performed. Two cameras were placed at the $3 \mathrm{~m}$ and $45 \mathrm{~m}$ from the first timing gate. The acceleration phase was recorded using a video camera (Canon XM-1 digital miniDV, Tokyo, Japan) operating at $50 \mathrm{~Hz}$. The maximum velocity phase was recorded using a high speed video camera (Redlake, Tucson, Arizona, USA) operating at $250 \mathrm{~Hz}$. The cameras were mounted on a rigid tripod at a height of $1.3 \mathrm{~m}$ and placed at a distance of $20 \mathrm{~m}$ from the middle of the athlete's lane. The optical axis of the cameras was perpendicular to the direction of running, and the field of view of the cameras was zoomed so that the athlete was visible in a $6-\mathrm{m}$ wide region. This field of view ensured that a complete running cycle (two steps) would be recorded. The movement space was calibrated with two $2.5 \mathrm{~m}$ high poles that were placed along the midline of the athlete's lane and $5 \mathrm{~m}$ apart.

Kwon3D biomechanical analysis software (Visol, Cheolsandong, Korea) was used to analyze the video images of the trials. Twenty-two body landmarks that defined a 14-segment model of the athlete were digitized in each image. The segmental data used were those proposed by de Leva (1996) for male adults. In the acceleration phase, the digitized images were interpolated to $100 \mathrm{~Hz}$ using fifth-order splines, and the 2D coordinates of the body landmarks and the athlete's centre of mass were calculated using the direct linear transform algorithm. Coordinate data were smoothed using a second-order Butterworth digital filter with a cutoff frequency of $12 \mathrm{~Hz}$, and the velocity of the athlete's centre of mass and joint angular velocities were calculated from the coordinate data using the finite differences method (Winter, 1990). The kinematic variables were measured at three instants during the stride: touchdown $\left(\mathrm{T}_{\text {down }}\right)$, midstance $\left(\mathrm{T}_{\text {mid }}\right)$, and takeoff $\left(\mathrm{T}_{\text {off }}\right)$. The instant of touchdown was the first frame in which the athlete's foot was in contact with the ground, the midstance was the frame nearest to when the athlete's center of mass passed directly over the toe of the foot, and the instant of takeoff was the first frame in which the athlete's foot was no longer in contact with the ground (Fig. 2). All digitizing was performed by the same operator to maximize the consistency of the dependent variables. Although in some instants of the digitizing process, there were hidden points (mainly the hip) on the side opposite to the camera, the reliability of intra-participant digitizing and inter-participant digitizing was very high. An intraclass correlation coefficient (ICC) value of 0.999 was obtained when three instants of the same video sequence were digitized five times, and an ICC value of 0.998 was obtained when two researchers digitized three instants of the same sequence.

\section{Isoinertial strength}

A modified Smith machine that consisted of a bar that moved freely on rollers in the vertical plane was used to measure maximal

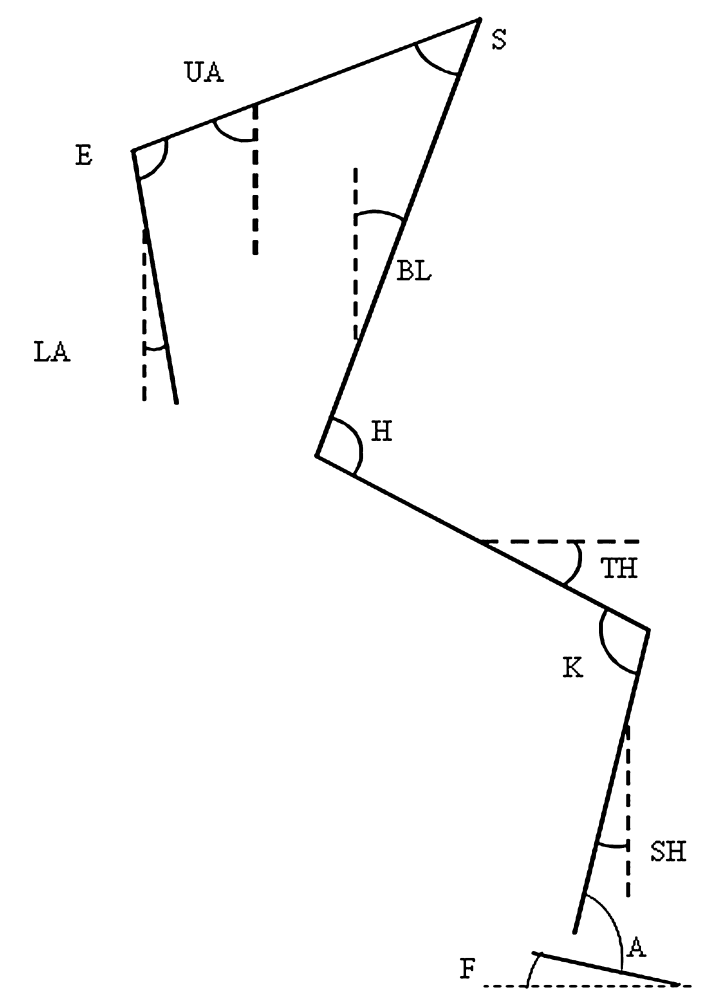

Fig. 2. Definitions of joint and segment angles (LA, lower arm; E, elbow; UA, upper arm; S, shoulder; BL, body lean; H, hip; TH, thigh; K, knee; SH, shank; A, ankle; and F, foot).

bilateral isoinertial strength of the lower limbs. The strength was assessed by a 1RM test in a half squat exercise $\left(90^{\circ}\right.$ knee angle). This variable was recorded as the maximum weight that the subjects were able to lift in the exercise. An assistant gave a 'go' signal when the lifter attained the proper joint angle (this procedure was practiced extensively in familiarization). For security, we limited the range of motion to $80^{\circ}$ knee angle with an adjustable chair. After the general warm-up, subjects performed a specific warm-up using 50\% (10 repetitions), 75\% (6 repetitions), and 85\% (3 repetitions) of their estimated 1RM. Following this warm-up, the subjects' resistances were fixed at a critical value of $5 \%$ below the expected 1RM and were gradually increased after each successful performance until failure. The interval between each trial was $3 \mathrm{~min}$ and $1 \mathrm{RM}$ was achieved within three to five attempts. In the tests, the last acceptable extension with the highest possible load was taken as $1 \mathrm{RM}$.

\section{Power-load curve}

On a modified Smith machine, a rotary encoder (Real Power, Globus, Codogne, Italy) attached to the barbell and interfaced with a computer allowed the recording of bar position with an accuracy of $0.002 \mathrm{~s}$; the system was calibrated prior to each testing session and bar velocity and power (using the measured load) were subsequently calculated.

Fifteen minutes after testing for the maximum strength of the lower limbs, the subjects were asked to perform five sets of three repetitions of half squat using resistances of 30\%, 45\%, 60\%, $70 \%$, and $80 \%$ of $1 \mathrm{RM}$ with 3 -min passive rest between sets. The subjects were spotted by an experienced lifter to ensure that maximum velocity was achieved safely and the subject was confident under the weight. Loud verbal encouragement was given 
Short-term sled towing training in athletes

throughout. The eccentric phase of the lift was performed over $3 \mathrm{~s}$ and was timed by a digital metronome, whereas the concentric phase was performed at maximum velocity. Because of the significant load lifted, the subjects were able to push maximally throughout the movement range without the bar escaping the subject's grip at the top of the movement; experienced spotters ensured that the bar was stopped at the top of its trajectory. Bar velocity and power during the concentric phase of the movement were measured for the exercise and for each repetition.

\section{Isokinetic strength}

An isokinetic dynamometer (Biodex 6000, New York, New York, USA) was used for the isokinetic strength tests. Each subject underwent a thorough and standardized familiarization session, including all tests, at least 1 week before being tested. The hip extensors and flexors in the dominant leg were tested concentrically. All movements were tested at $60^{\circ}, 180^{\circ}, 270^{\circ}$, and $450^{\circ} \%$ angular velocities. Each subject was measured in a standing position and stabilized with velcro straps. Joint range was determined by convenience of each subject, keeping in mind that range was reached close to the run-specific technique. The axis of rotation of the dynamometer lever arm was aligned with the anatomical axis of the hip, as described in the Biodex test manual. Both the 'dynamic ramping' (limb acceleration and deceleration) and 'gravity correction' features were used in all tests to avoid previously documented problems, such as torque overshoot and gravity effects. The dynamometer was calibrated, using the protocol from the Biodex 6000 manual, at the beginning of each test session.

At each test velocity, the subject performed between three and five submaximal warm-up trials followed by three maximal warm-up trials. The test started 1 min after the six warm-up trials had been completed. A recovery period of $90 \mathrm{~s}$ between test velocities was used. The trial in each test which had the greatest peak torque was taken as the measure of maximal strength.

\section{Training intervention}

The specific training phase was carried out for 4 weeks. All training groups completed eight sprint training sessions of $\sim 90 \mathrm{~min}$, spaced over 4 weeks (two sessions per week). Several previous longitudinal sprint training studies have shown this training frequency and duration sufficient for eliciting significant improvements in sprinting performance (Blazevich et al., 2003; Harrison \& Bourke, 2009; Clark et al., 2010). In addition to the experimental sprint training protocol, all subjects completed an identical periodized strength training program two days per week (on nonsprint training days) for the duration of the study as part of their regular off-season training program. The sprint and strength training sessions were structured as follows.

\section{Strength training}

All subjects lifted weights that allowed four sets of nine repetitions with 9RM (approximately $75 \%$ of $1 \mathrm{RM}$ ) in the first week. The training progressed to four sets of six repetitions with 6RM (approximately $85 \%$ of $1 \mathrm{RM}$ ) in the last week (we used this load because the athletes were at the beginning of the preparatory phase). The eccentric phase of each exercise was performed for approximately $3 \mathrm{~s}$, whereas the concentric phase was performed at maximum velocity. Three minutes of rest separated the sets. Subjects performed RT using the free-weight back squat to a $90^{\circ}$ knee angle as their dominant training exercise during the specific training phase. Athletes also performed supplementary exercises such unilateral hip extensions, standing calf raise and power clean.

\section{Sprints and jumps training}

The sprint trials were conducted on a RekortanM99 synthetic track in an outdoor athletics stadium. Participants wore their own athletic training clothes and spiked sprint shoes. Each training session began with a 30-min warm-up where all subjects performed a sprint-specific warm-up consisting of $8 \mathrm{~min}$ of running with a heart rate of $140 \mathrm{bpm}, 8 \mathrm{~min}$ of active stretching, $10 \mathrm{~min}$ of running technique exercises, and two to four submaximal and maximal short sprints. After the warm-up, subjects in the two groups completed the sprint training protocol listed in Table 2. Briefly, the sprint/jump sessions were divided into a: (a) flying sprint component consisting of resisted (WS) or UR sprints; and (b) jump/sprint component consisting of maximal forward bounding exercise over distances of 30-m or 50-m sprint from standing start. During the sprint component, subjects performed $30-\mathrm{m}$ flying sprints at maximum intensity using a run-in distance of $20 \mathrm{~m}$ from a standing start. (We used this distance because previous pilot studies showed that athletes were getting theirs maximum velocity prior to the $50 \mathrm{~m}$.) In the first session of each week, the flying sprint training was performed first and then the jumps. In the second, 50-m sprints at maximum intensity from a standing start were performed first and then the 30-m flying sprints. In the first week of training, one set of $3 \times 30$-m flying sprint runs were separated by $3 \mathrm{~min}$ of rest. One set of $3 \times 30-\mathrm{m}$ forward bounding exercise were also performed with $3 \mathrm{~min}$ of rest separating jumps, and 6 min separating exercises. By the end of the study, one set of $6 \times 30$-m flying sprint runs were separated by $3 \mathrm{~min}$ of rest. After that, one set of $6 \times 30$-m bounding exercises were performed (Table 2). In the second session, the same progression was followed (see Table 2). The WS group performed the same sprint/jump training, but the flying sprints sets were carried out with the sled towing. Thus, the total number of training sessions and sets performed by both training groups was the same. A qualified sprint coach who was unaware as to the group allocation of subjects supervised all sessions for each group.

The cooldown was always the same for all subjects and consisted of $5 \mathrm{~min}$ of slow running and $10 \mathrm{~min}$ of passive stretching.

\section{Statistical analysis}

Main and interaction effects were first analyzed using multivariate analyses of variance (ANOVA) with repeated measures. Significant time effects were further analyzed using paired samples $t$-tests. Interaction (time $\times$ group) effects were examined using independent samples $t$-tests on the change scores for each group (i.e., pre-post changes). In some instances, the assumption of equality of variance was violated, according to Levene's test of equality of variance. In these cases, unequal variances were assumed. Power $(1-\beta)$ and effect sizes $(d)$ were also established, $d$ were calculated using Cohen's $d$. An alpha level of $P \leq 0.05$ was set as the criterion for statistical significance for all analyses.

\section{Results}

\section{Sprint performance}

Repeated-measures ANOVA revealed a significant effect of time $\left(\mathrm{V}_{0-15}, P=0.05 ; \mathrm{V}_{15-30}, P=0.012 ; \mathrm{V}_{30-50}, P=\right.$ $0.019)$ but has not shown an interaction effect. $\mathrm{V}_{15-30}$ improved for the WS group $(0.20 \pm 0.25 \mathrm{~m} / \mathrm{s}, P=0.018$, $1-\beta=0.724, d=0.445)$, and the UR group improved $\mathrm{V}_{30-50}(0.17 \pm 0.23 \mathrm{~m} / \mathrm{s}, \quad P=0.030, \quad 1-\beta=0.625, \quad d=$ 
Alcaraz et al.

Table 3. Pre- and posttest scores (mean \pm SD) and changes for the average and maximum sprint velocities in the different sprint sections

\begin{tabular}{rlrlllrr}
\hline & & $V_{0-15}{ }^{*}(\mathrm{~m} / \mathrm{s})$ & $V_{15-30^{*}(\mathrm{~m} / \mathrm{s})}$ & $V_{30-50^{*}(\mathrm{~m} / \mathrm{s})}$ & $V_{0-30^{*}(\mathrm{~m} / \mathrm{s})}$ & $V_{0-50^{*}(\mathrm{~m} / \mathrm{s})} V_{\max }(\mathrm{m} / \mathrm{s})$ \\
\hline WS & Pre & $6.49 \pm 0.47$ & $8.49 \pm 0.67$ & $8.83 \pm 0.84$ & $7.80 \pm 0.60$ & $7.27 \pm 0.50$ & $8.97 \pm 0.89$ \\
& Post & $6.39 \pm 0.44$ & $8.69 \pm 0.69$ & $8.94 \pm 0.74$ & $7.85 \pm 0.58$ & $7.34 \pm 0.49$ & $8.96 \pm 0.85$ \\
& $\Delta$ & $-0.10 \pm 0.20$ & $0.20 \pm 0.25^{\dagger}$ & $0.11 \pm 0.29$ & $0.07 \pm 0.14$ & $0.05 \pm 0.16$ & $-0.01 \pm 0.27$ \\
UR & Pre & $6.72 \pm 0.35$ & $8.84 \pm 0.50$ & $9.12 \pm 0.56$ & $8.11 \pm 0.46$ & $7.58 \pm 0.42$ & $9.33 \pm 0.63$ \\
& Post & $6.64 \pm 0.25$ & $8.95 \pm 0.49$ & $9.29 \pm 0.46$ & $8.12 \pm 0.38$ & $7.58 \pm 0.30$ & $9.38 \pm 0.58$ \\
& $\Delta$ & $-0.09 \pm 0.23$ & $0.11 \pm 0.28$ & $0.17 \pm 0.23^{\dagger}$ & $0.00 \pm 0.27$ & $0.01 \pm 0.20$ & $0.05 \pm 0.24$
\end{tabular}

*Participants commenced from a line $1 \mathrm{~m}$ behind the first timing gate, therefore, mean velocity in the section $0-15 \mathrm{~m}$ is corresponding to the section 1-16 $\mathrm{m}$, and so on.

${ }^{\dagger}$ Significant difference between pre- and post-training $(P \leq 0.05)$.

$V$, average velocity; $V_{\max }$, maximum velocity; WS, weighted sled; UR, unresisted; $\Delta$, changes.

Table 4. Pre- and posttest scores (mean \pm SD) and changes for the kinematic parameters of stride length, stride frequency, landing distance (recorded in the second support), and ground contact time recorded in the stride 3 of the sprint acceleration phase

\begin{tabular}{clcccc}
\hline & & Stride length $(\mathrm{cm})$ & Stride frequency $(\mathrm{Hz})$ & Landing distance $(\mathrm{cm})$ & Contact time $(\mathrm{s})$ \\
\hline WS & Pre & $113.9 \pm 8.6$ & $3.75 \pm 0.43$ & $10.4 \pm 7.0$ & $0.19 \pm 0.03$ \\
& Post & $116.4 \pm 9.7$ & $3.69 \pm 0.29$ & $13.6 \pm 6.6$ & $0.21 \pm 0.01$ \\
& $\Delta$ & $2.5 \pm 5.0$ & $-0.1 \pm 0.3$ & $3.1 \pm 6.0$ & $0.02 \pm 0.03$ \\
UR & Pre & $110.6 \pm 10.3$ & $3.68 \pm 0.15$ & $3.3 \pm 7.3$ & $0.21 \pm 0.18$ \\
& Post & $111.7 \pm 10.4$ & $3.85 \pm 0.00$ & $6.4 \pm 7.0$ & $0.21 \pm 0.18$ \\
& $\Delta$ & $1.1 \pm 8.7$ & $0.2 \pm 0.2$ & $3.1 \pm 6.8$ & $0.00 \pm 0.01$ \\
\hline
\end{tabular}

WS, weighted sled; UR, unresisted; $\Delta$, changes.

Table 5. Pre- and posttest scores (mean \pm SD) and changes for the sprint kinematics in the acceleration phase (recorded in the second stride)

\begin{tabular}{|c|c|c|c|c|c|c|c|}
\hline \multirow[t]{2}{*}{ Variable } & \multirow[t]{2}{*}{ Instant } & \multicolumn{3}{|l|}{ Weighted sled } & \multicolumn{3}{|l|}{ Unresisted } \\
\hline & & Pre & Post & $\Delta$ & Pre & Post & $\Delta$ \\
\hline Body lean $\left(^{\circ}\right)$ & $\begin{array}{l}\mathrm{T}_{\text {down }} \\
\mathrm{T}_{\text {off }}\end{array}$ & $\begin{array}{l}38.7 \pm 5.4 \\
37.9 \pm 6.6\end{array}$ & $\begin{array}{l}46.2 \pm 8.1^{\dagger} \\
39.9 \pm 5.3\end{array}$ & $\begin{array}{l}7.5 \pm 3.3^{*} \\
2.3 \pm 4.9\end{array}$ & $\begin{array}{l}42.1 \pm 5.6 \\
40.0 \pm 3.7\end{array}$ & $\begin{array}{l}43.1 \pm 5.9 \\
39.5 \pm 4.2\end{array}$ & $\begin{array}{r}1.0 \pm 5.7 \\
-0.4 \pm 4.1\end{array}$ \\
\hline Thigh angle $\left({ }^{\circ}\right)$ & $\mathrm{T}_{\text {down }}$ & $\begin{array}{r}64.2 \pm 5.8 \\
120.7 \pm 3.4\end{array}$ & $\begin{aligned} 58.1 & \pm 11.8 \\
115.7 & \pm 6.5\end{aligned}$ & $\begin{array}{l}-6.1 \pm 13.2 \\
-4.9 \pm 7.0\end{array}$ & $\begin{aligned} 58.9 & \pm 10.3 \\
118.1 & \pm 8.0\end{aligned}$ & $\begin{array}{r}55.2 \pm 9.6 \\
119.2 \pm 3.3\end{array}$ & $\begin{aligned}-3.7 & \pm 13.2 \\
1.2 & \pm 7.0\end{aligned}$ \\
\hline Shank angle $\left({ }^{\circ}\right)$ & $\mathrm{T}_{\text {down }}$ & $\begin{array}{l}40.0 \pm 4.7 \\
60.4 \pm 2.9\end{array}$ & $\begin{array}{l}41.5 \pm 10.1 \\
70.3 \pm 13.8\end{array}$ & $\begin{array}{r}1.5 \pm 10.5 \\
10.2 \pm 16.3\end{array}$ & $\begin{array}{l}41.9 \pm 7.7 \\
70.9 \pm 11.1\end{array}$ & $\begin{array}{l}38.1 \pm 6.5 \\
66.2 \pm 5.1\end{array}$ & $\begin{array}{l}-3.9 \pm 11.0 \\
-4.7 \pm 10.9\end{array}$ \\
\hline Foot angle $\left({ }^{\circ}\right)$ & $\begin{array}{l}\mathrm{T}_{\text {down }} \\
\mathrm{T}_{\text {off }}\end{array}$ & $\begin{array}{l}12.0 \pm 4.4 \\
78.5 \pm 11.1\end{array}$ & $\begin{array}{c}9.0 \pm 4.3 \\
86.8 \pm 22.4\end{array}$ & $\begin{aligned}-2.9 & \pm 5.7 \\
7.5 & \pm 24.5\end{aligned}$ & $\begin{array}{l}11.4 \pm 5.9 \\
85.9 \pm 11.4\end{array}$ & $\begin{array}{l}10.7 \pm 8.9 \\
82.9 \pm 7.8\end{array}$ & $\begin{array}{l}-0.6 \pm 6.5 \\
-3.1 \pm 14.3\end{array}$ \\
\hline
\end{tabular}

* Significant difference between the training groups $(P \leq 0.01)$.

${ }^{\dagger}$ Significant difference between pre- and post-training $(P \leq 0.01)$.

$\mathrm{T}_{\text {down }}$, instant of touchdown; $\mathrm{T}_{\text {off, }}$ instant of takeoff.

0.389) (Table 3). Independent $t$-test did not show differences in the changes in WS vs UR.

\section{Sprint kinematics in the acceleration phase}

Repeated-measures ANOVA did not reveal a significant effect of time for none of the stride variables analyzed in the acceleration phase and has not shown an interaction effect (Table 4).

Sprint kinematics measures in the acceleration phase are listed in Table 5. ANOVAs revealed significant group $\times$ time interaction effects $(P=0.01)$ and betweengroup differences $(P=0.036,1-\beta=0.587, d=0.368)$ for body lean variable at touchdown. Body lean significantly increased for the WS around $7.5^{\circ}(P=0.003,1-\beta=$ $0.990, d=0.857)$.

\section{Sprint kinematics in the maximum velocity phase}

Table 6 shows the pre- and posttest results for intervention and control groups for the stride length, stride frequency, landing distance, and ground contact time recorded in the sprint maximum velocity phase. A significant group $\times$ time interaction effect was found for the stride length $(P=0.003)$ and landing distance $(P=0.03)$. In addition, between-group differences were 
Short-term sled towing training in athletes

Table 6. Pre- and posttest scores (mean $\pm \mathrm{SD}$ ) and changes for the kinematic parameters of stride length, stride frequency, landing distance, and ground contact time recorded in the sprint maximum velocity phase $(45 \mathrm{~m})$

\begin{tabular}{|c|c|c|c|c|c|}
\hline & & Stride length (cm) & Stride frequency $(\mathrm{Hz})$ & Landing distance $(\mathrm{cm})$ & Contact time (s) \\
\hline \multirow[t]{3}{*}{ WS } & Pre & $214.6 \pm 16.6$ & $4.29 \pm 0.30$ & $38.1 \pm 4.6$ & $0.113 \pm 0.01$ \\
\hline & Post & $220.3 \pm 16.8^{*}$ & $4.20 \pm 0.34$ & $41.2 \pm 3.5^{\dagger}$ & $0.115 \pm 0.01$ \\
\hline & $\Delta$ & $5.7 \pm 5.3$ & $-0.09 \pm 0.13$ & $3.0 \pm 3.2$ & $0.01 \pm 0.01$ \\
\hline \multirow{3}{*}{ UR } & Pre & $222.7 \pm 12.8$ & $4.16 \pm 0.16$ & $44.0 \pm 6.0$ & $0.124 \pm 0.01$ \\
\hline & Post & $226.0 \pm 16.0$ & $4.14 \pm 0.18$ & $44.5 \pm 4.4$ & $0.119 \pm 0.01$ \\
\hline & $\Delta$ & $3.2 \pm 5.2$ & $-0.02 \pm 0.18$ & $0.4 \pm 4.3$ & $-0.01 \pm 0.01^{*}$ \\
\hline
\end{tabular}

${ }^{*}$ Significant difference between the training groups $(P \leq 0.05)$.

${ }^{\dagger}$ Significant difference between pre- and post-training $(P \leq 0.05)$.

WS, weighted sled; UR, unresisted; $\Delta$, changes.

Table 7. Pre- and posttest scores (mean \pm SD) and changes for the sprint kinematics in the maximum velocity phase (45 m).

\begin{tabular}{|c|c|c|c|c|c|c|c|}
\hline \multirow[t]{2}{*}{ Variable } & \multirow[t]{2}{*}{ Instant } & \multicolumn{3}{|l|}{ Weighted sled } & \multicolumn{3}{|l|}{ Unresisted } \\
\hline & & Pre & Post & $\Delta$ & Pre & Post & $\Delta$ \\
\hline \multirow[t]{3}{*}{ Body lean $\left(^{\circ}\right)$} & $\mathrm{T}_{\text {down }}$ & $10.9 \pm 5.7$ & $9.3 \pm 4.3$ & $-1.7 \pm 3.8$ & $10.6 \pm 3.8$ & $9.9 \pm 4.1$ & $-0.6 \pm 4.9$ \\
\hline & $\mathrm{T}_{\text {mid }}$ & $11.3 \pm 3.9$ & $11.5 \pm 2.4$ & $0.2 \pm 4.5$ & $10.0 \pm 3.4$ & $12.4 \pm 4.0$ & $2.4 \pm 3.2$ \\
\hline & $\mathrm{T}_{\text {off }}$ & $2.8 \pm 4.5$ & $5.0 \pm 4.7$ & $2.2 \pm 4.7$ & $3.2 \pm 3.1$ & $5.2 \pm 3.8$ & $2.1 \pm 3.0$ \\
\hline \multirow[t]{3}{*}{ Thigh angle $\left({ }^{\circ}\right)$} & $\mathrm{T}_{\text {down }}$ & $60.2 \pm 4.1$ & $53.7 \pm 3.8^{*}$ & $-6.5 \pm 3.3$ & $55.7 \pm 4.8$ & $52.0 \pm 2.2^{*}$ & $-3.74 \pm 4.5$ \\
\hline & $\mathrm{T}_{\text {mid }}$ & $78.1 \pm 3.8$ & $75.2 \pm 3.8^{*}$ & $-2.9 \pm 4.2$ & $75.7 \pm 3.9$ & $73.2 \pm 2.9^{*}$ & $-2.5 \pm 3.4$ \\
\hline & $\mathrm{T}_{\text {off }}$ & $120.9 \pm 3.2$ & $120.1 \pm 3.7$ & $-0.8 \pm 3.3$ & $122.0 \pm 3.4$ & $119.5 \pm 4.6$ & $-2.5 \pm 6.3$ \\
\hline \multirow[t]{3}{*}{ Shank angle $\left({ }^{\circ}\right)$} & $\mathrm{T}_{\text {down }}$ & $-2.2 \pm 3.7$ & $-1.0 \pm 2.8$ & $1.2 \pm 4.3$ & $-1.9 \pm 4.2$ & $-1.1 \pm 4.1$ & $0.8 \pm 3.8$ \\
\hline & $\mathrm{T}_{\text {mid }}$ & $28.2 \pm 3.7$ & $33.7 \pm 2.7^{\star}$ & $5.5 \pm 3.4$ & $34.5 \pm 2.8$ & $36.0 \pm 3.9$ & $1.5 \pm 3.3$ \\
\hline & & $49.2 \pm 2.9$ & $50.9 \pm 2.5^{\star}$ & $1.7 \pm 2.1$ & $53.2 \pm 4.2$ & $54.2 \pm 3.4$ & $1.0 \pm 3.1$ \\
\hline \multirow[t]{3}{*}{ Foot angle $\left(^{\circ}\right)$} & $\mathrm{T}_{\text {down }}$ & $7.9 \pm 3.0$ & $7.9 \pm 2.9$ & $-0.1 \pm 4.4$ & $2.3 \pm 6.8$ & $3.7 \pm 7.9$ & $1.5 \pm 2.7$ \\
\hline & $\mathrm{T}_{\text {mid }}$ & $10.9 \pm 2.6$ & $11.7 \pm 2.5$ & $0.8 \pm 2.8$ & $9.6 \pm 2.0$ & $11.6 \pm 1.8$ & $2.0 \pm 3.2$ \\
\hline & $\mathrm{T}_{\text {off }}$ & $82.9 \pm 6.5$ & $82.9 \pm 5.4$ & $0.1 \pm 4.9$ & $83.2 \pm 4.0$ & $80.8 \pm 3.5$ & $-2.4 \pm 3.0$ \\
\hline
\end{tabular}

${ }^{*}$ Significant difference between pre- and post-training $(P \leq 0.05)$.

$T_{\text {down, }}$ instant of touchdown; $T_{\text {mid, }}$ instant of midstance; $T_{\text {off, instant of takeoff. }}$

found for contact time $(P=0.01, \quad 1-\beta=0.739$, $d=0.340)$. Stride length significantly increased for the resisted group around $5.7 \pm 5.3 \mathrm{~cm}(P=0.019,1-\beta=$ $0.741, d=0.566)$. This increase was similar to that produced in the landing distance $(P=0.009,1-\beta=0.841$, $d=0.552$ ).

Sprint kinematics measures in the maximum velocity phase are displayed in Table 7. ANOVAs revealed significant group $\times$ time interaction effects for thigh angle at $\mathrm{T}_{\text {down }}(P=0.001)$ and $\mathrm{T}_{\text {mid }}(P=0.006)$, and shank angle at $\mathrm{T}_{\text {mid }}(P=0.001)$ and $\mathrm{T}_{\text {off }}(P=0.033)$, however, has not shown an interaction effect. Thigh angle significantly decreased for both groups after training at $\mathrm{T}_{\text {down }}$ (WS: $P=0.001,1-\beta=1.0, d=0.815$; UR: $P=0.027,1-\beta=$ $0.654, d=0.437$ ) and at $\mathrm{T}_{\text {mid }}$ (WS: $P=0.05,1-\beta=0.490$, $d=0.343$; UR: $P=0.045,1-\beta=0.547, d=0.376$ ). Regarding shank angle, this kinematic variable only significantly increased for the WS group at $\mathrm{T}_{\text {mid }}(P=0.001$, $1-\beta=0.995, d=0.748)$ and $\mathrm{T}_{\text {off }}(P=0.031,1-\beta=0.625$, $d=0.420)$.

\section{Strength variables}

Repeated-measures ANOVA revealed a significant effect of time for maximum isoinertial strength and power
(1RM: $P=0.001 ; \mathrm{P}_{45 \%}, P=0.001 ; \mathrm{P}_{60 \%}, P=0.029 ; \mathrm{P}_{70 \%}$, $\left.P=0.011 ; \mathrm{P}_{80 \%}, P=0.045\right)$ but has not shown an interaction effect. Squat strength increased for the WS group $(P=0.001, \quad 1-\beta=1.0, d=0.955)$ and for the UR $(P=0.017,1-\beta=0.838, d=0.797)$ (Table 8). For the squat mechanical power (Table 8 ), there was an increase in WS group at $45 \%(P=0.001,1-\beta=0.993, d=0.993)$ and $70 \% \quad(P=0.009, \quad 1-\beta=0.884, d=0.707)$, and increase in UR at $30 \%(P=0.001,1-\beta=1.0, d=0.998)$. There were no between-group differences in the half squat power changes.

Repeated-measures ANOVA revealed a significant effect of time (hip flexion peak torque at $180^{\circ} / \mathrm{s}$ : $P=0.001 ; 270 \%$ s: $P=0.001 ;$ and $450 \%$ s: $P=0.002$ ) but has not shown an interaction effect. Isokinetic strength significantly increased for the WS group at $180^{\circ}$ and $270 \%$ s $(P=0.045, \quad 1-\beta=0.546, d=0.375 ; P=0.004$, $1-\beta=0.914, d=0.583$, respectively). Whereas in the UR group, isokinetic strength significantly increased at $180^{\circ}$, $270^{\circ}$, and $450^{\circ} / \mathrm{s} \quad(P=0.016,1-\beta=0.966, d=0.640$; $P=0.025, \quad 1-\beta=0.660, \quad d=0.409 ; \quad$ and $P=0.023$, $1-\beta=1.0, d=0.915$, respectively) (Table 9). There were no between-group differences in the half squat power changes. 
Alcaraz et al.

Table 8. Maximum isoinertial strength and concentric mechanical power in a half squat exercise at $30 \%, 45 \%, 60 \%, 70 \%$, and $80 \%$ of $1 \mathrm{RM}$

\begin{tabular}{|c|c|c|c|c|c|c|c|}
\hline & & 1RM (kg) & $P_{30 \%}(\mathrm{~W})$ & $P_{45 \%}(\mathrm{~W})$ & $P_{60 \%}(\mathrm{~W})$ & $P_{70 \%}(\mathrm{~W})$ & $P_{80 \%}(\mathrm{~W})$ \\
\hline \multirow[t]{3}{*}{ WS } & Pre & $133 \pm 37$ & $755 \pm 318$ & $937 \pm 382$ & $1155 \pm 589$ & $1232 \pm 486$ & $1345 \pm 739$ \\
\hline & Post & $161 \pm 37$ & $807 \pm 292$ & $1082 \pm 358$ & $1266 \pm 481$ & $1400 \pm 550$ & $1448 \pm 755$ \\
\hline & $\Delta$ & $29 \pm 7^{*}$ & $51 \pm 130$ & $145 \pm 79^{*}$ & $111 \pm 179$ & $169 \pm 118^{*}$ & $103 \pm 172$ \\
\hline \multirow[t]{3}{*}{ UR } & Pre & $142 \pm 26$ & $873 \pm 486$ & $1077 \pm 382$ & $1289 \pm 595$ & $1327 \pm 582$ & $1527 \pm 713$ \\
\hline & Post & $172 \pm 34$ & $966 \pm 482$ & $1361 \pm 566$ & $1445 \pm 513$ & $1486 \pm 634$ & $1750 \pm 745$ \\
\hline & $\Delta$ & $31 \pm 17^{*}$ & $93 \pm 5^{\star}$ & $284 \pm 191$ & $156 \pm 151$ & $159 \pm 227$ & $223 \pm 33$ \\
\hline
\end{tabular}

*Significant difference between pre- and post-training $(P \leq 0.05)$.

$P$, mechanical power; 1 RM, 1 repetition maximum. $\Delta$, differences.

Table 9. Pre- and posttest scores (mean \pm SD) and changes for the hip flexors isokinetic peak torque at $60^{\circ}, 180^{\circ}, 270^{\circ}$, and $450^{\circ} / \mathrm{s}$ angular velocities

\begin{tabular}{|c|c|c|c|c|c|}
\hline & & $\operatorname{TorqF}_{60^{\circ}}(\mathrm{N} / \mathrm{m})$ & $\operatorname{TorqF}_{180^{\circ}}(\mathrm{N} / \mathrm{m})$ & $\operatorname{TorqF}_{270^{\circ}}(\mathrm{N} / \mathrm{m})$ & $\operatorname{TorqF}_{450^{\circ}}(\mathrm{N} / \mathrm{m})$ \\
\hline \multirow[t]{3}{*}{ WS } & Pre & $161.1 \pm 51.6$ & $142.0 \pm 47.6$ & $123.6 \pm 41.7$ & $72.5 \pm 32.6$ \\
\hline & Post & $158.3 \pm 50.3$ & $155.2 \pm 43.3^{*}$ & $151.0 \pm 43.7^{*}$ & $91.6 \pm 27.1$ \\
\hline & $\Delta$ & $-2.8 \pm 29.2$ & $13.2 \pm 17.9$ & $27.3 \pm 24.3$ & $19.0 \pm 28.9$ \\
\hline \multirow[t]{3}{*}{ UR } & Pre & $158.1 \pm 54.2$ & $145.6 \pm 39.6$ & $129.6 \pm 31.5$ & $73.8 \pm 25.2$ \\
\hline & Post & $177.2 \pm 47.9^{*}$ & $174.1 \pm 57.5^{\star}$ & $164.5 \pm 57.6^{\star}$ & $101.1 \pm 41.7^{*}$ \\
\hline & $\Delta$ & $19.1 \pm 21.8$ & $28.4 \pm 22.4$ & $34.9 \pm 44.0$ & $27.3 \pm 33.8$ \\
\hline
\end{tabular}

*Significant difference between pre- and post-training $(P \leq 0.05)$.

TorqF, hip flexion peak torque; $\Delta$, differences.

Table 10. Pre- and posttest scores (mean \pm SD) and changes for the hip extensors isokinetic peak torque at $60^{\circ}, 180^{\circ}, 270^{\circ}$, and $450^{\circ} / \mathrm{s}$ angular velocities

\begin{tabular}{|c|c|c|c|c|c|}
\hline & & $\operatorname{Torq}_{60^{\circ}}(\mathrm{N} / \mathrm{m})$ & $\operatorname{Torq}_{180^{\circ}}(\mathrm{N} / \mathrm{m})$ & $\operatorname{Torq}_{270^{\circ}}(\mathrm{N} / \mathrm{m})$ & $\operatorname{Torq}_{450^{\circ}}(\mathrm{N} / \mathrm{m})$ \\
\hline \multirow[t]{3}{*}{ WS } & Pre & $121.3 \pm 47.1$ & $96.8 \pm 53.2$ & $67.3 \pm 41.6$ & $21.6 \pm 22.8$ \\
\hline & Post & $129.7 \pm 45.2$ & $104.3 \pm 43.5$ & $83.4 \pm 58.1$ & $26.1 \pm 24.7$ \\
\hline & $\Delta$ & $8.4 \pm 26.6$ & $7.5 \pm 34.4$ & $16.1 \pm 40.1$ & $2.9 \pm 32.6$ \\
\hline \multirow[t]{3}{*}{ UR } & Pre & $128.0 \pm 63.6$ & $97.6 \pm 45.2$ & $73.7 \pm 32.0$ & $24.6 \pm 34.6$ \\
\hline & Post & $138.9 \pm 62.4$ & $120.6 \pm 63.9$ & $79.0 \pm 32.0$ & $34.7 \pm 26.1$ \\
\hline & $\Delta$ & $10.9 \pm 26.4$ & $23.0 \pm 52.2$ & $5.3 \pm 27.4$ & $8.7 \pm 25.5$ \\
\hline
\end{tabular}

TorqE, hip extension peak torque; $\Delta$, differences.

Repeated-measures ANOVA did not reveal a significant effect of time for none of the hip extensors isokinetic peak torque, and has not shown an interaction effect (Table 10).

\section{Vertical jumps and sprint stiffness}

Repeated-measures ANOVA did not reveal a significant effect of time for the jumps performance, and has not shown an interaction effect (Table 11). Repeatedmeasures ANOVA did not reveal a significant effect of time for the relative jump mechanical power, the relative force applied in $100 \mathrm{~ms}\left(F_{100 \mathrm{~ms} / \mathrm{mm}}\right)$, and the stiffness variables. However, a between-group difference was found for $F_{100 \mathrm{~ms} / \mathrm{bm}}(P=0.025,1-\beta=0.698, d=0.595)$ (Table 12). Despite the not significant effect of time for vertical stiffness, a trend to signification $(P=0.081$, $1-\beta=0.420, d=0.422)$ was found for the UR group.
Table 11. Pre- and posttest scores (mean \pm SD) and changes for the performance (height) of the squat jump (SJ), modified squat jump (SJM), countermovement jump (CMJ), and drop jump (DJ)

\begin{tabular}{|c|c|c|c|c|c|}
\hline & & $S J_{h}(\mathrm{~cm})$ & SJM $_{\mathrm{h}}(\mathrm{cm})$ & $\mathrm{CMJ}_{\mathrm{h}}(\mathrm{cm})$ & $D J_{h}(\mathrm{~cm})$ \\
\hline \multirow[t]{3}{*}{ WS } & 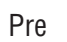 & & & & \\
\hline & Pos & 2 & & & \\
\hline & $\Delta$ & $0.3 \pm$ & $1.8 \pm 6.4$ & $0.7 \pm 2.4$ & $-1.1 \pm 4.6$ \\
\hline \multirow[t]{3}{*}{ UR } & Pre & $28.1 \pm 5.8$ & $20.1 \pm 3.6$ & $35.3 \pm 6.7$ & $33.5 \pm 3.9$ \\
\hline & Post & $27.9 \pm$ & $24.9 \pm$ & $36.5 \pm$ & $32.3 \pm 3.7$ \\
\hline & $\Delta$ & $-0.2 \pm 3.6$ & $4.8 \pm 6.0$ & $1.3 \pm 1.9$ & $-1.2 \pm 4.1$ \\
\hline
\end{tabular}

h, jump height; $\Delta$, differences.

\section{Discussion}

The purpose of this study was to assess the short-term effects produced by sled towing compared with traditional sprint training in well-trained athletes. The most 
Short-term sled towing training in athletes

Table 12. Pre- and posttest scores (mean \pm SD) and changes for the SJ, SJM, and CMJ relative to body mass mechanical power, force applied in 100 ms from the start of contraction of the a modified squat jump, and leg and vertical stiffness

\begin{tabular}{|c|c|c|c|c|c|c|c|}
\hline & & $\mathrm{SJ}_{\text {pow/bm }}(\mathrm{W} / \mathrm{kg})$ & $\mathrm{SJM}_{\text {pow/bm }}(\mathrm{W} / \mathrm{kg})$ & $\mathrm{CMJ}_{\text {pow/bm }}(\mathrm{W} / \mathrm{kg})$ & $F_{100 \mathrm{~ms} / \mathrm{bm}}(\mathrm{N} / \mathrm{kg})$ & $K_{\operatorname{leg}}(\mathrm{kN} / \mathrm{m})$ & $K_{\text {vertical }}(\mathrm{kN} / \mathrm{m})$ \\
\hline \multirow[t]{3}{*}{ WS } & Pre & $55.0 \pm 7.6$ & $58.5 \pm 7.1$ & $57.3 \pm 8.0$ & $31.5 \pm 0.9$ & $13.4 \pm 3.1$ & $156.9 \pm 37.9$ \\
\hline & Post & $55.0 \pm 7.8$ & $60.6 \pm 10.0$ & $57.6 \pm 8.1$ & $33.9 \pm 0.7$ & $13.2 \pm 3.2$ & $155.8 \pm 38.2$ \\
\hline & $\Delta$ & $0.0 \pm 3.7$ & $2.1 \pm 5.6$ & $0.3 \pm 4.6$ & $2.4 \pm 0.9$ & $-0.16 \pm 2.0$ & $-1.1 \pm 27.2$ \\
\hline \multirow[t]{3}{*}{ UR } & Pre & $54.5 \pm 3.4$ & $51.8 \pm 7.2$ & $52.3 \pm 6.3$ & $32.6 \pm 0.8$ & $10.7 \pm 2.8$ & $125.6 \pm 31.6$ \\
\hline & Post & $51.8 \pm 7.7$ & $58.6 \pm 7.4$ & $54.0 \pm 7.3$ & $30.9 \pm 3.8$ & $11.4 \pm 3.0$ & $136.9 \pm 33.5^{\dagger}$ \\
\hline & $\Delta$ & $-1.6 \pm 5.1$ & $5.6 \pm 5.3$ & $0.9 \pm 3.8$ & $-2.0 \pm 2.4^{*}$ & $0.8 \pm 1.9$ & $11.3 \pm 14.3$ \\
\hline
\end{tabular}

${ }^{\star}$ Significant difference between the training groups $(P \leq 0.05)$.

tTrend to signification $(P=0.081)$.

SJ, squat jump; SJM, modified squat jump; CMJ, countermovement jump; DJ, drop jump; body mass; $\Delta$, differences.

important finding from this study was that sled-towing training in well-trained athletes improved performance in the acceleration phase and stride length without producing significant changes in the kinematics of the sprint; however, there were no significant differences in relation to traditional sprint training.

\section{Sprint performance}

Both groups improved their times and their average speed in the transition phase $(15-30 \mathrm{~m})$. The WS group's improvements were significant $(P=0.018,1-\beta=0.724$, $d=0.445$ ). A possible cause of this significant improvement is that the combination of maximum strength training, sled towing, and jumping may cause adaptations in the neuromuscular system with a positive effect on force and rate of force development (RFD). Therefore, other possible mechanism for the improvements seen in the WS group could be due to an increment in RFD, Young et al. (1995) suggested that maximal force production and RFD were strongly related to tasks such as sprinting, where force production should be ranged between 80 and $160 \mathrm{~ms}$. These changes could also be influenced by slight changes in the sprint kinematic in the acceleration phase, as well as the increase in contact time $(P=0.019$, $1-\beta=0.741, d=0.566)$ and the inclination of the trunk (body lean; $P=0.003,1-\beta=0.990, d=0.857$ ) in the WS group. In fact, an increase in the contact time allows the athlete to apply force for a longer period of time. A greater body lean, allow athletes to apply more force in the anterior-posterior direction (Atwater, 1982), which is an important aspect in the acceleration phase. In the maximum velocity phase, both groups reduced their sprint times. The WS group reduced it by $1.3 \%$ and the UR group reduced it by $1.8 \%$. The UR group's reductions were significant. The WS group improved their performance in this phase possibly due to an increase in their stride length $(P=0.019,1-\beta=0.741, d=0.566)$, while the UR's group improvement was likely due to a decrease in contact time. Again, the causes of these effects are the combination of the maximum strength training with the specific strength training for the WS group and with the specific training for the UR group. The results obtained differ from those found by Zafeiridis et al. (2005), among physical education students, and by Spinks et al. (2007), in team sport athletes. However, the results are similar to those found by Kristensen et al. (2006) and Clark et al. (2010) in trained athletes. The differences found between the present study and previous studies analyzed could be due to the level of the participants (students vs athletes) and the differences in the magnitude of the training loads used on the sled.

\section{Sprint kinematics}

A possible short-, medium-, and long-term problem of using resisted methods is the possible permanent modification of the kinematics after using them. For the kinematic variables in the WS group in the third stride (initial phase of acceleration), a significant $7.4 \%$ decreases in the angle of the knee of the supporting limb and a significant $15.7 \%$ increase of the angle of trunk inclination were found. It has been reported that an excessive angle of the trunk lean could result in an increase in the landing distance (Korchemny, 1988). Therefore, the change in knee angle of the support leg is a direct consequence of increased trunk inclination for the WS group. The increase in the trunk inclination may be due to an adaptation produced by the athlete due to the load in the resisted sprint, which may allow the development of a better position to accelerate. Comparing the training effect of the WS group on trunk inclination with studies found in the literature that apply sled-tow training (Spinks et al., 2007) also an increase in the trunk inclination of the acceleration phase is found. So in this type of training, coaches should be aware of this aspect.

In the phase of maximum velocity $(45 \mathrm{~m})$, there were significant differences in the WS and UR groups that can benefit athletes' performance. The WS group significantly increased their stride length $2.7 \%$. The causes of the changes in stride length may reside in the significant 


\section{Alcaraz et al.}

increase in their landing distance. Most of the reviewed literature has focused on studying the effect of sled towing on the acceleration phase. Only the studies by Zafeiridis et al. (2005) and Clark et al. (2010) have looked at the maximum speed phase. The results found in these studies differ from those of our study. No improvements in the stride length at any stage were found for the WS group in these studies. An increase in the stride length in the maximum speed phase for the UR group was found by Zafeiridis et al. (2005). The authors of that study (Zafeiridis et al., 2005) were unable to explain the reasons for these improvements, and they argued that a possible explanation was the athletes' lack of experience. However, the data show that for the UR group, there was a significant decrease in contact time $(3.5 \%)$. The explanation for this decrease in contact time could be the improved vertical stiffness (Farley et al., 1998) and the increased intermuscular coordination of the lower body (Young, 2006). The contact time changed significantly between the pre- and posttest in the WS and the UR groups. The WS group's time increased slightly and the UR group decreased significantly. This finding may explain the statements by Kristensen et al. (2006). The authors describe the existence of a hypothetical relationship between force and velocities in the sprints (resisted or not). It appears that with resisted sprint training, high power are achieved at submaximum velocities (mechanical power is increased by increasing the force component), while traditional sprint training, high power are obtained at high velocities (increase in mechanical power by increasing the velocity component).

In relation to the kinematic variables in the maximum velocity phase, the observed differences are similar in both training groups at two of the three instants that were analyzed. Some of them are negative and some are positive for sprint performance. In the $\mathrm{T}_{\text {down }}$ instant, a decrease in the hip angle, knee, and thigh mean that athletes tend to run in a more 'seated' position during the contact phase of the stride. Thus, it could cause a decrease in the height of the COM and an increase in the vertical oscillation. These kinematic changes were found for both training groups, although mainly for the WS group, and are negative for performance. For the $T_{\text {mid }}$ moment, similar significant changes were found in some of the angles and lower-body segments. For support leg, a significant increase in knee flexion and leg angle and a significant decrease of the thigh angle were found. In the non-support leg, a significant increase in knee flexion was found. The variation of angles and segments in the $T_{\text {mid }}$ are the result of the position acquired by the subjects in the previous moment $\left(\mathrm{T}_{\text {down }}\right)$. A significant increase in knee flexion of the nonsupport leg was found in both groups. At the $\mathrm{T}_{\text {off }}$ instant, a significant increase in the angle support leg was found for the WS group. This modification is permanent throughout the support phase for this group and it is an effect to the previous moments. A significant reduction in the ankle and foot angle was found for the UR group. No experi- mental studies have been found which have studied the effects of training on kinematic variables in the maximum speed phase, thus it was not possible to compare this data with the scientific literature.

\section{Strength variables}

Data found in the present study show that resisted methods can be used as a form of training to improve the mechanical power by increasing the force applied in the sprint. Although the ground reaction force were not analyzed in this study, both the force-velocity curve and the force applied at $100 \mathrm{~ms}$ after performing a vertical jump, has been positively affected for the WS group. In this study, peak mechanical power when performing a squat exercise has been modified with both types of workouts. Significant increases in peak power at $45 \%(P=0.001,1-\beta=0.993, d=0.993)$, as well as $70 \%$ of $1 \mathrm{RM}(P=0.009,1-\beta=0.884, d=0.707)$ were found for the WS group, while the UR group improved significantly at $30 \%$ of $1 \mathrm{RM}(P=0.001,1-\beta=1.0$, $d=0.998)$. Possible explanations for these improvements in power with higher loads in the WS group are that sled towing affects power through an improvement in strength; while the UR training improved lowerbody strength through improvement in velocity. Therefore, resisted training could be a convenient method of transition to change the power curve from high strength percentages to lower percentages. Jones et al. (2001) and McBride et al. (2002) found that training by trying to maximize power with low loads improved power and the velocity with low loads. Additionally, this improvement in power at low loads shows a trend towards significance in performance improvement over 20-m sprinting (McBride et al., 2002). In summary, a common assumption of many authors is that power is maximized at loads of $30-45 \%$ 1RM. However, there are large interindividual and exercise-specific differences in the load where peak power occurs. Hence, it would seem important to specifically identify the load where peak power occurs for each individual subject on specific exercises to adequately investigate the effects of peak power training on force, power, and functional performance.

Significant increases were observed in the peak torques for hip flexion at the intermediate angular velocities for the WS group and at all velocities for the UR group. However, when the results are presented as relative to body mass, significant increases were only found at the angular velocity of $180^{\circ} / \mathrm{s}$ for the WS group and the angular velocity of $60^{\circ}$ and $180^{\circ}$ s for the UR group. The main cause of these results could be an increase in the lower body isoinertial maximum strength in both training groups. Results are similar to other studies that have observed strength increases in training groups using similar training loads (McBride et al., 2002; Harris et al., 2008). 
Short-term sled towing training in athletes

Vertical jumps and sprint stiffness

In the present study, no significant improvements in the performance (jump height) of any of the jumps that were tested (SJ, SJM, CMJ, and DJ) were found. Similar results have been found in studies with similar training protocols (Blazevich et al., 2003). However, statistically significant improvements in power done to execute an SJM by the UR groups have been observed. The WS groups significantly improved the force applied at $100 \mathrm{~ms}$ in the SJM execution. It is possible that these variables are more related to power application than to the height of the jump itself. In fact, the best predictor of maximum speed is the maximum force generated during the $100 \mathrm{~ms}$ from the beginning of a concentric jump with load (Young et al., 1995). Similar results were found by Harrison and Bourke (2009). They have shown that the results of the SJ indicate a significant group $\times$ time interaction effect for starting strength $(P=0.004)$. The data show that the WS training group improved starting strength post-intervention, whereas the control group got worse $(P=0.025,1-\beta=0.698, d=0.595)$. The validity of isolation starting strength has been corroborated by electromyography research and confirms the suggestions that starting strength is, in part, determined by the innate qualities of the neuromuscular apparatus, particularly the ratio of fast- to slow-twitch fibers in the muscle (Siff, 2000), and specialization of the neuromuscular system to develop starting strength is determined chiefly by the magnitude of external resistance.

No significant differences between the pre- and posttest in stiffness of the support leg, or in vertical stiffness for the WS and UR groups were found. However, a trend toward significance $(P=0.081)$ in the vertical stiffness of the UR group were found. More studies are needed to know whether there are any relationships between these variables. On the other hand, it has been shown that an increase in vertical stiffness causes a decrease in contact time (Farley et al., 1998). MacMahon and Cheng (1990) revealed that contact time decreased as horizontal and vertical velocities increased, stating that vertical stiffness also increased in a linear trend when vertical velocity increased. In fact, one of the most important findings in our study is that the UR group significantly reduced their contact time in the maximum speed phase. Therefore, a possible explanation for this improvement lies in the increase in vertical stiffness.

\section{Perspectives}

Clearly, the subjects in the present study were a welltrained sample. In this sense, it should be considered that these results are only applicable to those athletes with similar characteristics to the participants of this research. Additionally, it is important to remark that there were no clear differences between groups, for that reason, caution should be used when comparing resisted vs traditional sprint training data. After that, we concluded that the WS training produced an increase in the athletes' performance, in the transition phase $(15-30 \mathrm{~m})$. The UR training raised the athletes' performance in the maximum velocity phase $(30-50 \mathrm{~m})$. The WS training yielded an increase in body lean, in the acceleration phase. In the maximum velocity phase, an enhancement in stride length and landing distance was found. The UR training decreased, in the maximum velocity phase, contact time, and increased body lean. Both groups experimented an adoption of a 'sitting' position after training. Finally, and following the recommendations made by Brughelli and Cronin (2008) regarding stiffness in sprint training, we found that a slight increase in vertical stiffness in the UR group was produced. Probably, a long training period should be needed to get significant adaptations in this variable.

Key words: athletics, sprint training, specific strength, resisted methods.

\section{Acknowledgements}

This research is supported by a grant by the Spanish Ministry of Economy and Competitiveness (DEP2011-28727).

\section{References}

Alcaraz PE, Palao JM, Elvira JLL. Determining the optimal load for sprint training with sled towing. J Strength Cond Res 2009: 23: 480-485.

Alcaraz PE, Palao JM, Elvira JLL, Linthorne NP. Effects of three types of resisted sprint training devices on the kinematics of sprinting at maximum velocity. J Strength Cond Res 2008: 22: 890-897.

Alcaraz PE, Palao JM, Elvira JLL, Linthorne NP. Effects of a sand running surface on the kinematics of sprinting at maximum velocity. Biol Sport 2011: 28: 95-100.
Atwater AE. Kinematic analyses of sprinting. Track Field Quart Rev 1982: 82: 12-16.

Bangsbo J, Norregaard L, Thosoe F. Activity profile of competition soccer. Can J Sport Sci 1991: 16: 110-116.

Behm DG, Sale DG. Intended rather than actual movement velocity determines velocity-specific training response. J Appl Physiol 1993: 74: 359-368.

Blazevich AJ, Gill ND, Bronks R, Newton RU. Training-specific muscle architecture adaptation after 5-wk training in athletes. Med Sci Sports Exerc 2003: 35: 2013-2022.
Brughelli M, Cronin J. A review of research on the mechanical stiffness in running and jumping: methodology and implications. Scand J Med Sci Sports 2008: 18: 417-426.

Clark KP, Stearne DJ, Walts CT, Miller AD. The longitudinal effects of resisted sprint training using weighted sleds vs. weighted vests. J Strength Cond Res 2010: 24: 3287-3295.

Cronin JB, Hansen KT. Resisted sprint training for the acceleration phase of sprinting. Strength Cond J 2006: 28: $42-51$.

Cronin JB, Hansen K, Kawamori N, McNair P. Effects of weighted vests 


\section{Alcaraz et al.}

and sled towing on sprint kinematics. Sports Biomech 2008: 7: 160-172.

Delecluse C. Influence of strength training on sprinting performance: current findings and implications for training. Sports Med 1997: 24: 147-156.

Delecluse C, Van Coppenolle H, Willens E, Van Leemputte D, Diels R, Gordis $\mathrm{M}$. Influence of high-resistance and high-velocity training on sprint performance. Med Sci Sports Exerc 1995: 27: 1203-1209.

Farley CT, Houdijk HH, Van Strien C, Louie M. Mechanism of leg stiffness adjustment for hopping on surfaces of different stiffnesses. J Appl Physiol 1998: 85: 1044-1055.

Harris NK, Cronin JB, Hopkins WG, Hansen KT. Relationship between sprint times and the strength/power outputs of a machine squat jump. J Strength Cond Res 2008: 22: 691-698.

Harris RC, Edwards RH, Hultman E, Nordesjo LO, Nylind B. The time course of phosphorylcreatine resynthesis during recovery of the quadriceps muscle in man. Pflugers Arch 1976: 367: 137-142.

Harrison AJ, Bourke G. The effect of resisted sprint training on speed and strength performance in male rugby players. J Strength Cond Res 2009: 23: 275-283.

Hay JG. The biomechanics of sports techniques. 4th edn. London: Prentice Hall International, 1993.

Jones K, Bishop P, Hunter G, Fleisig G. The effects of varying resistancetraining loads on intermediate- and high-velocity-specific adaptations. J Strength Cond Res 2001: 15: 349-356.

Kafer R, Adamson G. Methods for maximising speed development. Strength Cond Coach 1994: 2: 9-11.

Kaneko M, Fuchimoto T, Toji H, Suei K. Training effect of different loads on the force-velocity relationship and mechanical power output in human muscles. Scand J Sports Sci 1983: 5: 50-55.

Korchemny R. Training with the objective to improve stride length. NSCA J 1988: 10: $21-25$.

Kristensen GO, van den Tillaar R, Ettema GJC. Velocity specificity in early-phase sprint training. J Strength Cond Res 2006: 20: 833-837.

Letzelter M, Sauerwein G, Burger R. Resistance runs in speed development. Mod Athl Coach 1995: 33: 7-12.

de Leva P. Adjustments to ZatsiorskySeluyanov's segment inertia parameters. J Biomech 1996: 29: 1223-1230.

Lockie RG, Murphy AJ, Spinks CD. Effects of resisted sled towing on sprint Kinematics in field-sport athletes. J Strength Cond Res 2003: 17: 760-767.

McBride JM, Triplett-McBride T, Davie A, Newton RU. The effect of heavyvs. light-load jump squats on the development of strength, power, and speed. J Strength Cond Res 2002: 16: 75-82.

McMahon TA, Cheng GC. The mechanics of running: how does stiffness couple with speed? J Biomech 1990: 23 (Suppl. 1): 65-78.

Mero A, Komi P. EMG, Force, and power analysis of sprint-specific strength exercises. J Appl Biomech 1994: 10: $1-13$.

Morin JB, Dalleau G, Kyrolainen H, Jeannin T, Belli A. A simple method for measuring stiffness during running. J Appl Biomech 2005: 21: 167-180.

Murray A, Aitchison TC, Ross G, Sutherland K, Watt I, McLean D, Grant $\mathrm{S}$. The effect of towing a range of relative resistances on sprint performance. J Sports Sci 2005: 23: 927-935.

Plisk SS. Speed, agility, and speed-endurance development. In: Baechle TR, Earle RW, eds. Essentials of strength training and conditioning. Champaign, IL: Human Kinetics, 2000: 474-485.

Rutherford OM, Jones DA. The role of learning and coordination in strength training. Eur J Appl Physiol Occup Physiol 1986: 55: 100-105.

Sheppard J. The use of resisted and assisted training methods for speed development: coaching considerations. Mod Athl Coach 2004: 42: 9-13.

Siff MC. Biomechanical foundations of strength and power. In: Zatsiorsky $\mathrm{VM}$, ed. Biomechanics in sport. London: Blackwell Scientific, 2000: 103-139.

Spinks CD, Murphy AJ, Spinks WL, Lockie RG. The effects of resisted sprint training on acceleration performance and kinematics in soccer, rugby union, and Australian football players. J Strength Cond Res 2007: 21: 77-85.

Volkov I, Lapin V. Analysis of the velocity curve in sprint running. Med Sci Sports 1979: 11: 322-327.

Winter DA. Biomechanics and motor control of human movement. 2nd edn. New York: Wiley-Interscience, 1990.

Young W, McLean B, Ardagna J. Relationship between strength qualities and sprinting performance. J Sports Med Phys Fitness 1995: 35: 13-19.

Young WB. Transfer of strength and power training to sports performance. Inter J Sports Physiol Performance 2006: 1: 74-83.

Young WB, Benton B, Duthie G, Pryor J. Resistance training for short sprints and maximum-speed sprints. Strength Cond J 2001: 23: 7-13.

Zafeiridis A, Saraslanidis P, Monou V, Ioakimidis P, Dipla K, Kellis S. The effects of resisted sled-pulling sprint training on acceleration and maximum speed performance. J Sports Med Phys Fitness 2005: 45: 284-290. 